ASTHMA

\title{
Small airways function and molecular markers in exhaled air in mild asthma
}

\author{
S Battaglia, H den Hertog, M C Timmers, S P G Lazeroms, A M Vignolat, K F Rabe, V Bellia, \\ P S Hiemstra, P J Sterk
}

Thorax 2005;60:639-644. doi: 10.1136/thx.2004.035279

See end of article for authors' affiliations ..............

Correspondence to: Professor P J Sterk, Lung Function Laboratory C2-P Leiden University Medical Centre (LUMC), P O Box 9600, NL-2300 RC Leiden, The Netherlands; p.j.sterk@lumc.nl

Received

27 September 2004

Accepted 24 March 2005
Background: Several studies suggest that the periphery of the lung is the major site of inflammation in asthma. Fractional exhaled nitric oxide ( $\mathrm{FeNO}$ ) and 8-isoprostane have been proposed as biomarkers of inflammation and oxidative stress. We therefore hypothesised that small airway dysfunction in asthma is of inflammatory origin that can be detected by molecular markers in exhaled air. To test this hypothesis, we examined the relationship of FeNO and 8-isoprostane in exhaled air with small airways function as assessed by the single breath nitrogen test.

Methods: Sixteen patients (14 women) with mild atopic asthma (forced expiratory volume in 1 second $>80 \%$ predicted) of mean (SD) age 23.0 (5.5) years participated in a cross sectional study. FeNO was recorded by chemiluminescence and 8-isoprostane was measured by ELISA in concentrated exhaled breath condensate. The slope of phase III $\left(\delta N_{2}\right)$ and the closing volume $(\mathrm{CV})$ were assessed from the single breath washout curve.

Results: The median FeNO level was 30.4 ppb (range 10.1-82.8), the median 8-isoprostane concentration in exhaled breath condensate was $2.2 \mathrm{pg} / \mathrm{ml}$ (range 1.6-2.7), and the mean (SD) $\delta \mathrm{N}_{2}$ value was 1.1 $(0.4) \% \mathrm{~N}_{2} /$ l. FeNO was positively associated with $\delta \mathrm{N}_{2}\left(r_{\mathrm{s}}=0.54, \mathrm{p}=0.032\right)$ while 8-isoprostane was inversely correlated with $\mathrm{FEV}_{1} \%$ predicted $\left(r_{s}=-0.58 ; p=0.017\right)$ and $\mathrm{CV}$ as a percentage of vital capacity $\left(r_{\mathrm{s}}=0.58 ; \mathrm{p}=0.019\right)$.

Conclusions: FeNO and 8-isoprostane in exhaled air are associated with small airways function in mild asthma. This suggests that these markers reflect small airway inflammation and favours a role for them as disease markers that is complementary to spirometry in the monitoring of patients with asthma.
A sthma is a chronic airway disease characterised by episodic symptoms of variable severity that are associated with functional alterations and pathological abnormalities such as airway inflammation and remodelling. ${ }^{1}$ Airway inflammation is present in all forms of asthma including mild and asymptomatic cases, ${ }^{2}$ and involves central as well as peripheral airways. ${ }^{3}$ In cases of fatal and non-fatal asthma the central as well as the distal airways exhibit profound pathology, ${ }^{45}$ infiltration with $\mathrm{T}$ lymphocytes and eosinophils being most prominent in the distal part of the respiratory tract. ${ }^{3}$ However, other authors have reported relatively large numbers of inflammatory cells or structural alterations in the proximal bronchi. ${ }^{6}$

It has recently been shown that molecular markers can be assessed in exhaled breath and that these may detect airway inflammation in asthma. ${ }^{7}$ Exhaled nitric oxide (NO) is currently the most widely used marker in exhaled breath. Indeed, fractional exhaled nitric oxide (Feno) levels are increased in asthma even in mild and asymptomatic conditions. ${ }^{78}$ FenO derives from endogenous NO production by NO synthases present in airway epithelium and inflammatory cells. ${ }^{9}$ Even though it is likely that Feno originates from the intrapulmonary airways in asthma, ${ }^{10}$ it is still unclear whether it mirrors small airways inflammation in this disease. Exhaled breath condensate (EBC) is another source of products of airway inflammation and oxidative stress, ${ }^{7}$ and it has been shown that exhaled 8-isoprostane, a marker of lipid peroxidation, is increased in asthmatic patients compared with controls. ${ }^{11}$ Again, it is unknown whether markers detected in the EBC arise from large or small airways.

The role of peripheral airway pathology in asthma is incompletely understood because of the sporadic availability of surgical lung tissue. Pathological changes in the small airways can be detected indirectly by physiological tests. ${ }^{12}$ Among these, the single breath nitrogen test can be used to evaluate the presence of uneven ventilation. ${ }^{13}$ In smokers the single breath nitrogen test has strongly been anchored to peripheral airways pathology, being more sensitive than any other physiological measurement in detecting early small airways pathology. ${ }^{14}$ In asthma In't Veen et al ${ }^{15}$ recently showed that airway closure as measured by the single breath nitrogen test can discriminate between severe asthmatic patients with and without recurrent exacerbations, even when measured during clinically stable episodes. This is indicative of functional impairments in the periphery of the lung in asthma.

On this basis, we postulated that small airway dysfunction in asthma is of inflammatory origin that can be detected by molecular markers of inflammation in exhaled air. We addressed this hypothesis by examining the association of Feno and 8-isoprostane in EBC with functional impairment in the periphery of the lung as measured by the single breath nitrogen test in patients with asthma.

\section{METHODS \\ Subjects}

Twenty non-smoking or ex-smoking ( $<5$ pack-years) atopic subjects with a doctor's diagnosis of intermittent or mild

Abbreviations: $\mathrm{CV}$, closing volume; $\mathrm{EBC}$, exhaled breath condensate; $\mathrm{FeNO}$, fractional exhaled nitric oxide; $\mathrm{FEV}_{1}$, forced expiratory volume in 1 second; $\mathrm{FVC}$, forced vital capacity; $\mathrm{PC}_{20} \mathrm{MCh}$, provocative concentration of methacholine causing a $20 \%$ fall in $\mathrm{FEV}_{1}$.

${ }^{\dagger}$ Deceased December 2004. 
persistent asthma were recruited. All patients reported one or more asthma symptom during the previous 12 months. The patients had a baseline forced expiratory volume in 1 second $\left(\mathrm{FEV}_{1}\right)>80 \%$ of predicted and they all had bronchial hyperresponsiveness as shown by a provocative concentration of methacholine causing a $20 \%$ fall in $\mathrm{FEV}_{1}\left(\mathrm{PC}_{20} \mathrm{MCh}\right)$ of $<8 \mathrm{mg} / \mathrm{ml} .{ }^{16}$ Their atopic status was determined by skin prick tests (Soluprick, ALK, Benelux). The patients were clinically stable for at least 1 month before the study and none had a history of a recent $(\leqslant 4$ weeks) respiratory infection. The patients had not used inhaled or oral corticosteroids for at least 2 months before the study and 13 of them had used short acting $\beta_{2}$ agonists on demand only.

We subsequently performed an additional control experiment in 15 healthy subjects to examine whether any of the observed associations between exhaled markers and small airways function were confined to asthma. All the control subjects were free from chronic respiratory symptoms, without current or previous diagnosis of asthma, and were lifelong non-smokers except for one ex-smoker who had smoked 2.5 pack-years.

The study was approved by the Leiden University Medical Center ethics committee and all patients gave their written informed consent.

\section{Study design}

The study was of a cross sectional design and was performed on 2 days. The first day was a screening day to check all inclusion and exclusion criteria. During the screening a clinical questionnaire, skin prick test, spirometric tests, and a methacholine challenge were performed in each patient. On the second day exhaled Feno measurements, a single breath nitrogen test, body box plethysmography, baseline spirometric tests, and collection of EBC were performed in this sequence.

\section{Lung function}

Spirometric testing was performed with a dry rolling seal spirometer (Morgan Spiroflow, Morgan, UK). Acceptability and reproducibility of $\mathrm{FEV}_{1}$ and forced vital capacity (FVC) were evaluated according to European Respiratory Society (ERS) guidelines. ${ }^{17} \mathrm{FEV}_{1}$ was reported in litres, as percentage of predicted value ( $\mathrm{FEV}_{1} \%$ pred), and as percentage of $\mathrm{FVC}$ $\left(\mathrm{FEV}_{\mathrm{I}} / \mathrm{FVC} \%\right)$. Reference values were obtained from Quanjer et al. ${ }^{17}$ Total lung capacity (TLC), residual volume (RV), and functional residual capacity (FRC) were measured using a constant volume plethysmograph (Jaeger, Germany) by panting at $1 \mathrm{~Hz}$, also according to ERS recommendations. ${ }^{17}$

Methacholine challenge was performed following standardised methodology ${ }^{16}$ using serial doubling concentrations of methacholine bromide $(0.03-8 \mathrm{mg} / \mathrm{ml}$, Janssen Pharmaceutica, Beerse, Belgium).

\section{Small airways function}

Small airways function was assessed by the single breath nitrogen test using a dry rolling seal spirometer (Morgan Spiroflow) filled with 100\% oxygen and equipped with a nitrogen meter (Morgan) connected to the mouthpiece allowing continuous sampling, as described previously. ${ }^{13} 1518$ During the test each patient performed a slow full inspiratory and expiratory vital capacity (VC) manoeuvre at a flow rate of $0.5 \mathrm{l} / \mathrm{s}$. The constant flow was ensured by a mechanical flow regulator. The expiratory nitrogen concentration $\left(\% \mathrm{~N}_{2}\right)$ was plotted against lung volume (between TLC and RV) producing the expiratory nitrogen washout curve. ${ }^{13}{ }^{18}$ The slope of the nitrogen alveolar plateau $\left(\delta \mathrm{N}_{2}\right.$, phase III) was calculated by drawing the best fit line through phase III of the expiratory volume-concentration curve, ${ }^{13}$ and was expressed as $\% \mathrm{~N}_{2} / \mathrm{l}$. One expert operator (PJS), who was unaware of the patients' characteristics, manually drew all lines. This procedure has been validated in our laboratory, showing good within and between observer reproducibility in the slope of phase III (intraclass correlation coefficient, $R \mathrm{i}=0.94$ and 0.99 , respectively) and in closing volume $(R \mathrm{i}=0.93$ and 0.94). The first departure from this straight line was considered as indicative of airway closure, allowing the calculation of closing volume (CV, phase IV) and closing capacity $(\mathrm{CC}=\mathrm{RV}+\mathrm{CV}) .{ }^{15}{ }^{18}$ The measurements were only accepted if the $\mathrm{VC}$ during the single breath nitrogen test was within a $10 \%$ range of VC measured by spirometric testing. $\mathrm{CV}$ and $\mathrm{CC}$ were expressed as the ratio of $\mathrm{VC}$ (CV/VC) and TLC (CC/TLC), respectively.

\section{Exhaled NO}

Exhaled NO (Feno) levels were determined as previously described, ${ }^{19}$ following guidelines for the online single breath method $^{2021}$ and using a chemiluminescence online analyser (Sievers NOA 270B, Sievers, Boulder, Colorado, USA). During the measurement the subjects inspired "NO-free" air $(<2 \mathrm{ppb})$. The subjects were asked to perform a slow vital capacity manoeuvre with a constant expiratory flow rate of $100 \mathrm{ml} / \mathrm{s}^{19}$ using online visual monitoring. Measurements were discarded if the expiratory flow varied by more than $10 \%$ from target flow. An expiratory resistance of $5 \mathrm{~cm} \mathrm{H}_{2} \mathrm{O}$ was applied in order to prevent nasal NO contamination. Expired NO was sampled continuously from the centre of the flow with a sample flow of $440 \mathrm{ml} / \mathrm{min}$. The expiratory flow was measured by a pneumotachograph (Lilly principle, Erich Jaeger GmbH, Würzburg, Germany). Exhaled NO concentrations were determined at a 10 second plateau and expressed as parts per billion. Three successive manoeuvres were recorded for each subject at 1 minute intervals and the mean value of the three tests was used for statistical analysis.

\section{$E B C$ collection and analysis}

EBC was collected (EcoScreen, Jaeger, Germany) while the patient was breathing room air through a mouthpiece connected to a two way non-rebreathing valve and to a saliva trap. Each patient was asked to breath at a normal frequency and tidal volume for 15 minutes wearing a nose clip. This allowed about $2 \mathrm{ml}$ of condensate to be collected from the patient.

The collected fluid was immediately subdivided into $600 \mu \mathrm{l}$ aliquots in Eppendorf tubes which were instantaneously cooled with ice cold 2-methylbutane and then directly transferred to $-80^{\circ} \mathrm{C}$ pending analysis.

Pilot experiments performed in our laboratory and studies from other institutes ${ }^{22}$ have shown very low 8-isoprostane concentrations in EBC samples (close to the detection limit) from subjects similar to those participating in the present study. 8-isoprostane in EBC was therefore concentrated using an affinity sorbent (8-isoprostane affinity sorbent, Cayman Chemical, Ann Arbor, MI, USA). Briefly, $500 \mu \mathrm{l}$ EBC was incubated with $100 \mu \mathrm{l}$ sorbent for 60 minutes at room temperature. After centrifugation and washing of the sorbent, bound 8-isoprostane was eluted from the sorbent using $95 \%$ ethanol. The eluate was lyophilised by vacuum centrifugation and re-suspended in $165 \mu \mathrm{l}$ of enzyme linked immunosorbent assay (ELISA) buffer (8-isoprostane EIA kit, Cayman Chemical) to obtain a threefold concentrated solution. The concentration of 8 -isoprostane was assessed by ELISA (Cayman Chemical; lower limit of detection $5 \mathrm{pg}$ / $\mathrm{ml}$ ) and used to calculate the concentration in the original sample before the concentration procedure. All samples were analysed in duplicate and the mean intra-assay coefficient of variation was $7.7 \%$ (range $1.0-18.9 \%$ ). In addition, separate spiking experiments were performed by adding $50 \mu \mathrm{l} 8$ isoprostane ( $500 \mathrm{pg} / \mathrm{ml}$; standard from 8-isoprostane EIA kit) 
to $450 \mu \mathrm{l}$ thawed EBC collected from volunteer subjects. These experiments showed good recovery of added 8isoprostane when the non-concentrated procedure was used (recovery $>90 \%$ ), whereas recovery was low when using the affinity sorbent (about 60\%). Interestingly, recovery in the affinity sorbent procedure was near $100 \%$ using phosphate buffered saline instead of EBC, suggesting that some components of EBC interfere with binding of 8-isoprostane to the affinity sorbent.

The mean intra-assay coefficient of variation for the subsequent control experiments in healthy subjects was $5.2 \%$ (range $0.7-10.3 \%$ ). In 10 subjects from this control group we assessed the recovery of 8-isoprostane in EBC and observed a mean recovery of $88 \%$ (range $57-115 \%$ ). Because this study was performed separately from the original study in asthmatics, we have not analysed the absolute values of 8 -isoprostane between both groups.

\section{Statistical analyses}

Data are presented as mean (SD) or median (range) depending on whether they were normally distributed. The relationships between variables are expressed as Spearman rank correlation coefficient $\left(r_{\mathrm{s}}\right)$; differences at $\mathrm{p}$ values of $<0.05$ were considered to be statistically significant.

\section{RESULTS}

Sixteen patients of mean (SD) age 23.0 (5.5) years (male/ female ratio 2/14) completed the study. From the initial 20 subjects, one dropped out because of an asthma exacerbation on the test day, one was excluded due to the use of nasal steroids 5 days before the test, and another two subjects were excluded because their VC measured during the single breath nitrogen test differed by more than $10 \%$ from the VC measured by baseline spirometry.

The characteristics of the patients who completed the study are shown in table 1. Mean (SD) $\mathrm{FEV}_{1}$ was 97.3 (12.6)\% and $\mathrm{PC}_{20} \mathrm{MCh}$ ranged between 0.05 and $4.18 \mathrm{mg} / \mathrm{ml}$ (geometric mean $0.45 \mathrm{mg} / \mathrm{ml}$ ), which is indicative of mild to severe airway hyperresponsiveness. In accordance with this, FenO levels were high with a median of $30.4 \mathrm{ppb}$ (range 10.182.8 ), whereas the single breath nitrogen test showed mean (SD) $\delta \mathrm{N}_{2}$ values of $1.1(0.4) \% \mathrm{~N}_{2} / \mathrm{l}$ and a mean (SD) CV/VC value of $8.6(5.7) \%$. As described earlier, 8-isoprostane measurements were obtained from EBC samples that were concentrated threefold; after correction for this, the median 8 -isoprostane value was $2.2 \mathrm{pg} / \mathrm{ml}$ (range 1.6-2.7).

Interestingly, Feno levels were positively correlated with $\delta \mathrm{N}_{2}$ values $\left(r_{\mathrm{s}}=0.54, \mathrm{p}=0.032\right.$; fig $\left.1 \mathrm{~A}\right)$, whereas there was no significant correlation between $\mathrm{FeNO}$ and baseline $\mathrm{FEV}_{1} \%$ pred (fig $1 \mathrm{~B}$ ), $\mathrm{PC}_{20} \mathrm{MCh}, \mathrm{CV} / \mathrm{VC}$, or CC/TLC (lowest $\mathrm{p}$ value $=0.16$ )

The concentration of 8-isoprostane in EBC was inversely correlated with $\mathrm{FEV}_{1} \%$ pred $\left(r_{\mathrm{s}}=-0.58, \mathrm{p}=0.017\right.$; fig $\left.2 \mathrm{~A}\right)$ and positively correlated with $\mathrm{CV} / \mathrm{VC}\left(r_{\mathrm{s}}=0.58, \mathrm{p}=0.019\right.$; fig $2 \mathrm{~B})$. There were no correlations between 8 -isoprostane and Feno, $\delta \mathrm{N}_{2}, \mathrm{CC} / \mathrm{TLC}$, or $\mathrm{PC}_{20} \mathrm{MCh}$ (lowest $\mathrm{p}$ value $=0.05 \mathrm{l}$ )
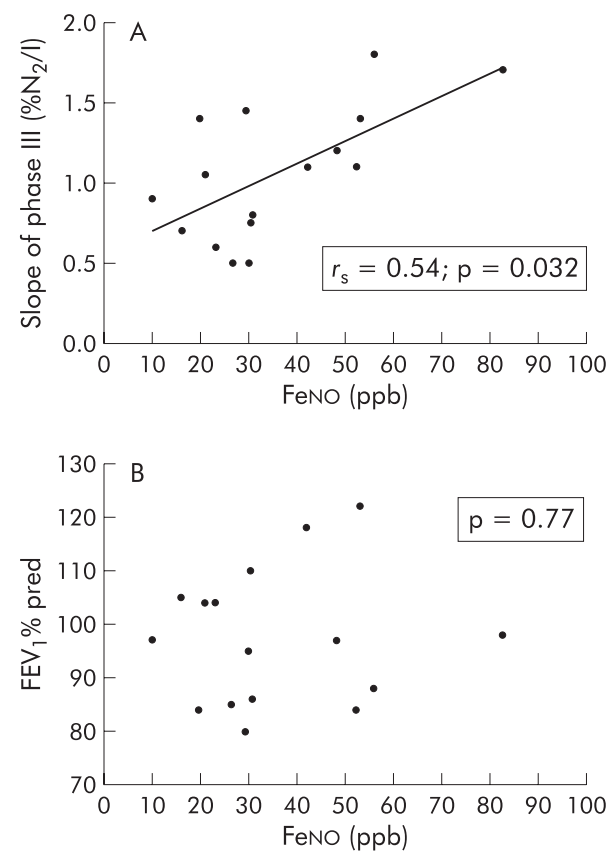

Figure 1 (A) Correlation between exhaled nitric oxide ( $\mathrm{FeNO}$ ) concentration in ppb and uneven ventilation $\left(\delta \mathrm{N}_{2}\left(\% \mathrm{~N}_{2} / l\right)\right)$. (B) Correlation between exhaled nitric oxide ( $\mathrm{FeNO}$ ) concentration in ppb and $\mathrm{FEV}_{1}$ (\% of predicted value).

Table 1 Characteristics of study subjects

\begin{tabular}{|c|c|c|c|c|c|c|c|c|c|c|}
\hline $\begin{array}{l}\text { Patient } \\
\text { no }\end{array}$ & $\begin{array}{l}\text { FEV }_{1} \\
\text { (\% pred) }\end{array}$ & $\begin{array}{l}\text { FEV }_{1} / \text { FVC } \\
(\%)\end{array}$ & $\begin{array}{l}\mathrm{PC}_{20} \mathrm{MCh} \\
(\mathrm{mg} / \mathrm{ml})\end{array}$ & $\begin{array}{l}\text { RV } \\
\text { (\% pred) }\end{array}$ & $\begin{array}{l}\text { TLC } \\
\text { (\% pred) }\end{array}$ & $\begin{array}{l}\text { FeNO } \\
\text { (ppb) }\end{array}$ & $\begin{array}{l}\text { 8-isoprostane* } \\
\text { (pg/ml) }\end{array}$ & $\begin{array}{l}\delta \mathrm{N}_{2} \\
\left(\% \mathrm{~N}_{2} / \mathrm{I}\right)\end{array}$ & $\begin{array}{l}\text { CV/VC } \\
(\%)\end{array}$ & $\begin{array}{l}\mathrm{CC} / \mathrm{TLC} \\
(\%)\end{array}$ \\
\hline 1 & 118 & 90.7 & 0.55 & 123 & 117 & 42.3 & 2.0 & 1.10 & 0.00 & 28.34 \\
\hline 2 & 105 & 81.2 & 4.18 & 106 & 110 & 16.3 & 2.0 & 0.70 & 3.89 & 29.86 \\
\hline 3 & 98 & 87.9 & 0.46 & 66 & 90 & 82.8 & 1.6 & 1.70 & 4.27 & 23.62 \\
\hline 4 & 88 & 83.2 & 0.86 & 78 & 88 & 56.1 & 2.7 & 1.80 & 9.92 & 31.77 \\
\hline 5 & 84 & 86.6 & 1.88 & 91 & 84 & 19.9 & 2.7 & 1.40 & 21.40 & 44.54 \\
\hline 6 & 84 & 70.3 & 0.18 & 124 & 98 & 52.5 & 2.0 & 1.10 & 16.39 & 40.38 \\
\hline 7 & 97 & 83.2 & 0.33 & 84 & 94 & 48.4 & 2.2 & 1.20 & 7.24 & 29.67 \\
\hline 8 & 122 & 89.5 & 0.05 & 96 & 112 & 53.3 & 2.0 & 1.40 & 3.25 & 25.88 \\
\hline 9 & 80 & 76.9 & 0.17 & 142 & 98 & 29.5 & 2.5 & 1.45 & 15.06 & 43.40 \\
\hline 10 & 104 & 72 & 0.69 & 79 & 113 & 23.4 & 2.3 & 0.60 & 14.85 & 31.01 \\
\hline 11 & 97 & 75.6 & 0.4 & 125 & 112 & 10.1 & 2.3 & 0.90 & 9.13 & 26.40 \\
\hline 12 & 85 & 72.1 & 0.06 & 66 & 94 & 26.7 & 2.3 & 0.50 & 6.55 & 24.51 \\
\hline 13 & 95 & 77.8 & 1.46 & 72 & 96 & 30.2 & 2.0 & 0.50 & 5.19 & 24.49 \\
\hline 14 & 110 & 78.5 & 0.41 & 126 & 115 & 30.6 & 2.0 & 0.75 & 9.69 & 41.50 \\
\hline 15 & 86 & 80.8 & 0.28 & 96 & 92 & 31.0 & 2.2 & 0.80 & 4.10 & 31.25 \\
\hline 16 & 104 & 84.2 & 1.29 & 74 & 98 & 21.2 & 2.0 & 1.05 & 7.52 & 26.55 \\
\hline Mean (SD) & $97.3(12.6)$ & $80.6(6.3)$ & $0.45+(3.3)$ & $97(24.6)$ & 101 (10.7) & $30.4 \ddagger$ & $2.1 \ddagger$ & $1.1(0.4)$ & $8.6(5.7)$ & $31.4(7.1)$ \\
\hline
\end{tabular}

$\mathrm{FEV}_{1} \%$ pred, forced expiratory volume in 1 second as percentage of predicted; $\mathrm{PC}_{20} \mathrm{MCh}$, provocative concentration of methacholine causing a $20 \%$ fall in $\mathrm{FEV}$; $\mathrm{RV}$, residual volume; $\mathrm{TLC}$, total lung capacity; FeNO, fractional exhaled nitric oxide; $\delta \mathrm{N}_{2}$, slope of the nitrogen alveolar plateau (phase III); $\mathrm{CV} / \mathrm{VC}$, closing volume as percentage of vital capacity; CC/TLC closing capacity as percentage of total lung capacity.

*Note that the values result from correction for the concentration factor (threefold). †Geometric mean (SD).

$\ddagger$ Median. 
In the control group mean (SD) $\mathrm{FEV}_{1} \%$ pred was 105.1 (10.7)\%, Feno levels ranged from 0.6 to $17.0 \mathrm{ppb}$ (median $8.6 \mathrm{ppb}$ ), the single breath nitrogen test showed a mean $\delta \mathrm{N}_{2}$ value of $1.2(0.4) \% \mathrm{~N}_{2} / \mathrm{l}$ and a CV/VC of $9.3(5.2) \%$. The median 8-isoprostane value was $3.6 \mathrm{pg} / \mathrm{ml}$ (range 2.9-7.6) after correction for the threefold concentration used in the sample preparation. There were no significant correlations between the exhaled markers and lung function measures in the healthy subjects (lowest $\mathrm{p}$ value $=0.54$ ).

\section{DISCUSSION}

Our results indicate that exhaled molecular markers of inflammation and oxidative stress are associated with functional evidence of small airway involvement in intermittent/mild persistent asthma. Exhaled NO levels are positively correlated with non-homogeneous emptying of lung units, as reflected by a steeper slope of phase III, but are not correlated with spirometric measurements. Furthermore, 8-isoprostane levels in EBC are increased in patients with more prominent airway closure, as shown by a positive correlation with CV/VC. This suggests that FenO and 8isoprostane may originate in part from small airways, thereby potentially providing complementary information to spirometry in the management of intermittent/mild persistent asthma.

The novel finding of this study is the association of exhaled markers of inflammation and oxidative stress (Feno and 8isoprostane) with indices of small airways function $\left(\delta \mathrm{N}_{2}\right.$ and CV/VC, respectively). Interestingly, we observed an inverse correlation between 8-isoprostane in EBC and $\mathrm{FEV}_{1}$, whereas Feno levels did not correlate with 8-isoprostane. The latter result differs from previous studies on EBC in adult asthmatics, ${ }^{11}$ and is presumably due to differences in clinical characteristics, age, or EBC analysis. Moreover, we have shown that the association of markers in exhaled air (FenO and 8-isoprostane) with lung function was only observed in asthmatic subjects and not in healthy controls.
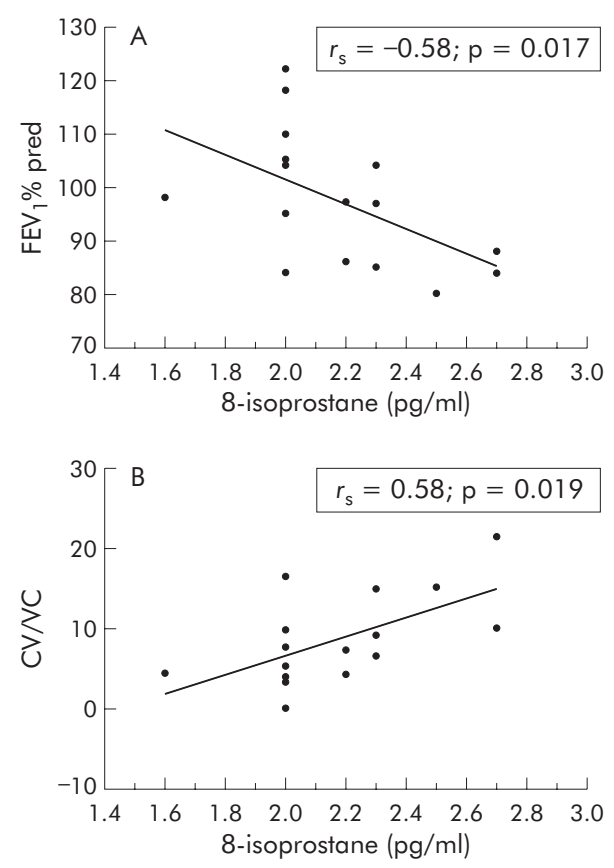

Figure 2 (A) Correlation between 8-isoprostane in exhaled breath condensate $\left(\mathrm{pg} / \mathrm{ml}\right.$ ) and $\mathrm{FEV}_{1}$ (\% of predicted value). (B) Correlation between 8 -isoprostane in exhaled breath condensate $(\mathrm{pg} / \mathrm{ml})$ and closing volume as percentage of vital capacity (CV/VC).
In this study particular attention was paid to methodological aspects such as patient selection. None of the patients used steroids and all had well documented disease by previous doctor's diagnosis, presence of symptoms during the last 12 months, and hyperresponsiveness to methacholine. The patients had intermittent/mild persistent asthma which is compatible with the Feno levels being higher than $10 \mathrm{ppb}$ (that is, above the range for normal subjects). ${ }^{21}$ Although it may be argued that $\delta \mathrm{N}_{2}$ values overlapped the normal range as reported from general population subjects, ${ }^{13}{ }^{18}$ it should be considered that these values ranged 3.6fold from $0.5 \%$ to $1.8 \% \mathrm{~N}_{2} / \mathrm{l}$ (table 1 ), which can be considered sufficient to reveal mild uneven ventilation in patients with mild asthma.

Levels of 8-isoprostane in EBC in asthmatics ranged from 1.6 to $2.7 \mathrm{pg} / \mathrm{ml}$. These levels are lower than those previously reported by Montuschi et al ${ }^{11}$ for EBC (mean $33.7 \mathrm{pg} / \mathrm{ml}$ in mild asthma). However, in a more recent study the latter investigators also found lower 8-isoprostane concentrations in mild asthmatics (mean values $10.4-12.8 \mathrm{pg} / \mathrm{ml}$ at baseline). ${ }^{23}$ Moreover, 8 -isoprostane (or 8 -epi-PGF $2 \alpha$ ) is one of the $\mathrm{F}_{2}$-isoprostanes, which have a mean (SE) basal concentration of $0.9 \quad(0.2) \mathrm{pg} / \mathrm{ml}$ in bronchoalveolar lavage fluid. ${ }^{24}$ Furthermore, in some previous studies the values of nonconcentrated samples in which no 8-isoprostane was detected were arbitrarily set at the lower limit of detection of the assay. We cannot exclude the possibility that this may have led to an overestimation of mean values, so the EBC levels of 8-isoprostane seen in this study seem to be consistent with the literature.

In our study particular attention was paid to laboratory methods using internal standard operating procedures specifically designed for EBC collection and storage as well as for 8-isoprostane measurements. The study was preceded by repeated pilot experiments which showed that it was essential to include a concentration step (threefold) in the procedure to analyse 8-isoprostane in EBC; the 8-isoprostane values reported in this study were therefore obtained after correcting for the concentration factor. Using non-concentrated samples we obtained very low values that were just above or around the detection limit of the assay, yielding inconsistent data as also observed by others. ${ }^{22}$ With regard to the recovery of added 8-isoprostane in spiking experiments, we observed a recovery of about $60 \%$ in subjects with asthma and $88 \%$ in healthy controls. This indicates that recovery in EBC from healthy subjects is higher than in asthmatics, with a large inter-subject variability. This may suggest that 8isoprostane levels are underestimated in asthmatics. Future studies need to include assessment of recovery of 8isoprostane levels in each individual EBC, which should be used for correction of the measured values. Finally, given the fact that the recruitment and all measurements of the control group were done on a separate and subsequent occasion, we did not analyse the differences between asthmatics and controls.

Our findings support previous observations on changes in peripheral lung function in asthma as assessed by multiple breath nitrogen washout, which is a test specifically designed to quantify impaired acinar ventilation distribution. ${ }^{25}$ Validation of the single breath nitrogen test in relation to histological features of small airways inflammation is lacking in asthma because of the limited availability of peripheral lung tissue in this disease. However, this has been studied in detail in smokers ${ }^{14}$ in whom non-homogeneous ventilation was observed, not only in the presence of emphysema and/or severe small airways disease, but also in patients with mild small airways disease. ${ }^{14}$ Even if non-homogeneous ventilation in the central airways might have influenced our results, the data in smokers indicate that $\delta \mathrm{N}_{2}$ is the physiological 
marker that is most strongly associated with small airways disease. ${ }^{14}$

How should we interpret the association between small airways function and FeNO/8-isoprostane levels in exhaled breath? Exhaled NO reflects endogenous production of NO by NO synthases, which are present in the (large) airways of patients with asthma. ${ }^{26}$ The main site of inducible (type II) NO synthase expression is the airway epithelium, and it is also observed in several inflammatory cells. ${ }^{27}$ It is therefore conceivable that epithelial cells of small airways and inflammatory cells infiltrating peripheral airways wall contribute to the levels of NO measured in expired air. Chronic inflammation can be associated with modified structure of the small airway walls, which contributes to the nonhomogeneous obstruction of small airways. ${ }^{4}$ This condition is likely to induce non-homogeneous emptying of peripheral lung units ${ }^{28}$ which can be measured as a steeper phase III $\left(\delta \mathrm{N}_{2}\right) \cdot{ }^{29}$ Although a significant statistical correlation does not directly indicate that FeNo and 8-isoprostane originate from the small airways, we believe that our findings may provide indirect support for the hypothesis that this is the site of origin of these markers. However, we cannot exclude alternative hypotheses. Firstly, FenO and $\delta \mathrm{N}_{2}$ might reflect abnormalities of distinct areas in the lung while both being driven by shared but widespread inflammatory mechanisms. Secondly, it is possible that uneven ventilation by itself affects Feno in asthma. This could be addressed by including uneven ventilation in validated mathematical models. ${ }^{30}$ Thirdly, even the correlations between 8-isoprostane and lung function tests could have occurred by chance. However, we believe that the biological plausibility of the observed inverse correlation between 8-isoprostane levels and $\mathrm{FEV}_{1} \%$ pred and its positive correlation with CV/VC indirectly support the accuracy of our measurements. Taken together, our data support the need to compare directly FenO and 8isoprostane levels with small airways disease, even in the very limited resection material available from young patients with mild asthma.

The role of peripheral airways disease in asthma is largely unknown, partly because of the relative sporadic availability of peripheral lung tissue. Several authors have therefore proposed alternative methods for studying small airways in asthma, such as bronchoalveolar lavage, transbronchial biopsy, ultrathin bronchoscopy, induced sputum, high resolution computed tomography, or magnetic resonance imaging with hyperpolarised ${ }^{3} \mathrm{He}$ gas. ${ }^{12}$ Some of these methods are invasive and are therefore potentially more hazardous to patients than simple physiological measurements. However, these methods may explore different aspects of small airways physiology, biology and pathology and therefore may be considered as complementary techniques in assessing peripheral airways.

What are the clinical implications of our study? Firstly, our findings underline the relevance of assessing small airways function even in patients with mild degrees of asthma. Secondly, our results favour a role for exhaled markers (FenO and 8-isoprostane) as indices of the functional status of small airways that appears to be complementary to spirometry in monitoring patients with asthma. It needs to be emphasised that our study was performed in patients with atopic intermittent/mild persistent asthma; caution should be taken in extrapolating the present observations to non-atopic patients or to those with different degrees of disease severity.

In conclusion, in patients with mild atopic asthma not using inhaled steroids we have shown that exhaled NO levels increase with increasing unevenness of ventilation and 8isoprostane levels in EBC are higher in patients with more prominent airway closure. These data suggest that exhaled molecular markers of inflammation and oxidative stress reflect small airways function in asthma. Further investigations are needed to assess a direct link between Feno and 8isoprostane and the morphology and inflammatory activity in the small airways.

\section{ACKNOWLEDGEMENTS}

The authors thank A C van der Linden for expert technical assistance.

\section{Authors' affiliations}

S Battaglia, H den Hertog, M C Timmers, S P G Lazeroms, K F Rabe,

P S Hiemstra, P J Sterk, Department of Pulmonology, Leiden University Medical Centre (LUMC), Leiden, The Netherlands

S Battaglia, A M Vignola, V Bellia, Istituto di Medicina Generale e Pneumologia, Cattedra di Malattie dell'Apparato Respiratorio, Università di Palermo, Palermo, Italy

This study was funded by Università di Palermo and Leiden University Medical Centre (LUMC), Valeas Italy and Italian Nitric Oxide Club (INOC).

Competing interests: $\mathrm{SB}$ has received unrestricted educational grants from Valeas Italy, GlaxoSmithKline and AstraZeneca. HdH, MCT, SPGL have no competing interests. AMV has been a consultant, participated in advisory board meetings and received lecture fees from GlaxoSmithKline and AstraZeneca. KFR has been a consultant, participated in advisory board meetings and received lecture fees from AstraZeneca, Boehringer, Pfizer, Novartis, AltanaPharma, MSD, and GlaxoSmithKline. VB has participated in advisory board meetings and received lecture fees from GlaxoSmithKline. The Department of Pulmonology (and thereby KFR, PSH and PJS as staff members) have received grants from AltanaPharma, Novartis, Bayer, AstraZeneca, Pfizer, MSD, Exhale Therapeutics and GSK in the years 2001-2004. The Istituto di Medicina Generale e Pneumologia (and thereby AMV and VB as staff members) have received grants from Bayer, Rhone Poulenc, AstraZeneca, MSD, and Aventis Pharma in the years 2001-2004.

\section{REFERENCES}

1 NHLBI/WHO. Global strategy for asthma management and prevention Workshop Report. Publication No 02-3659. Bethesda, MD: NIH, 2002. Available at www.ginasthma.com.

2 Bousquet J, Jeffery PK, Busse WW, et al. Asthma. From bronchoconstriction to airways inflammation and remodeling. Am J Respir Crit Care Med 2000;161:1720-45

3 Hamid Q, Song $Y$, Kotsimbos TC, et al. Inflammation of small airways in asthma. J Allergy Clin Immunol 1997; 100:44-51

4 Carroll N, Elliot J, Morton A, et al. The structure of large and small airways in nonfatal and fatal asthma. Am Rev Respir Dis 1993;147:405-10.

5 Mauad T, Silva LF, Santos MA, et al. Abnormal alveolar attachments with decreased elastic fiber content in distal lung in fatal asthma. Am J Respir Crit Care Med 2004;170:857-62.

6 Haley KJ, Sunday ME, Wiggs BR, et al. Inflammatory cell distribution within and along asthmatic airways. Am J Respir Crit Care Med 1998;158:565-72.

7 Kharitonov SA, Barnes PJ. Exhaled markers of pulmonary disease. Am J Respir Crit Care Med 2001; 163:1693-722.

8 Alving K, Weitzberg E, Lundberg JM. Increased amount of nitric oxide in exhaled air of asthmatics. Eur Respir J 1993;6:1368-70.

9 Silkoff PE, Robbins RA, Gaston B, et al. Endogenous nitric oxide in allergic airway disease. J Allergy Clin Immunol 2000;105:438-48.

10 Massaro AF, Mehta S, Lilly CM, et al. Elevated nitric oxide concentrations in isolated lower airway gas of asthmatic subjects. Am J Respir Crit Care Med 1996;153:1510-4.

11 Montuschi P, Corradi M, Ciabattoni G, et al. Increased 8-isoprostane, a marker of oxidative stress, in exhaled condensate of asthma patients. Am J Respir Crit Care Med 1999;160:216-20.

12 Shaw RJ, Djukanovic R, Tashkin DP, et al. The role of small airways in lung disease. Respir Med 2002;96:67-80.

13 Buist AS, Ross BB. Predicted values for closing volumes using a modified single breath nitrogen test. Am Rev Respir Dis 1973;107:744-52.

14 Cosio M, Ghezzo H, Hogg JC, et al. The relations between structural changes in small airways and pulmonary-function tests. N Engl J Med 1978:298:1277-81.

15 In't Veen JC, Beekman AJ, Bel EH, et al. Recurrent exacerbations in severe asthma are associated with enhanced airway closure during stable episodes. Am J Respir Crit Care Med 2000;161:1902-6.

16 Sterk PJ, Fabbri LM, Quanjer PH, et al. Airway responsiveness. Standardized challenge testing with pharmacological, physical and sensitizing stimuli in adults. Report Working Party Standardization of Lung Function Tests, European Community for Steel and Coal. Official Statement of the European Respiratory Society. Eur Respir J Suppl 1993;16:53-83.

17 Quanjer PH, Tammeling GJ, Cotes JE, et al. Lung volumes and forced ventilatory flows. Report Working Party Standardization of Lung Function Tests, European Community for Steel and Coal. Official Statement of the European Respiratory Society. Eur Respir J Suppl 1993;16:5-40. 
18 Sterk PJ, Quanjer PH, van Zomeren BC, et al. The single breath nitrogen test in epidemiological surveys; an appraisal. Bull Eur Physiopathol Respir $1981 ; 17: 381-97$.

19 de Gouw HW, Hendriks J, Woltman AM, et al. Exhaled nitric oxide (NO) is reduced shortly after bronchoconstriction to direct and indirect stimuli in asthma. Am J Respir Crit Care Med 1998;158:315-9.

20 American Thoracic Society. Recommendations for standardized procedures for the on-line and off-line measurement of exhaled lower respiratory nitric oxide and nasal nitric oxide in adults and children-1999. Am J Respir Crit Care Med 1999; 160:2104-17.

21 Kharitonov S, Alving K, Barnes PJ. Exhaled and nasal nitric oxide measurements: recommendations. The European Respiratory Society Task Force. Eur Respir J 1997; 10:1683-93.

22 Van Hoydonck PG, Wuyts WA, Vanaudenaerde BM, et al. Quantitative analysis of 8-isoprostane and hydrogen peroxide in exhaled breath condensate. Eur Respir J 2004;23:189-92.

23 Kharitonov SA, Donnelly LE, Montuschi P, et al. Dose-dependent onset and cessation of action of inhaled budesonide on exhaled nitric oxide and symptoms in mild asthma. Thorax 2002;57:889-96.
24 Dworski R, Murray JJ, Roberts $\amalg$ 2nd, et al. Allergen-induced synthesis of F(2)isoprostanes in atopic asthmatics. Evidence for oxidant stress. Am J Respir Crit Care Med 1999; 160:1947-51

25 Verbanck S, Schuermans D, Paiva M, et al. Nonreversible conductive airway ventilation heterogeneity in mild asthma. J Appl Physiol 2003;94:1380-6.

26 Ricciardolo FL, Timmers MC, Geppetti P, et al. Allergen-induced impairment of bronchoprotective nitric oxide synthesis in asthma. J Allergy Clin Immunol 2001; 108:198-204.

27 Robbins RA, Hadeli K, Nelson D, et al. Nitric oxide, peroxynitrite, and lower respiratory tract inflammation. Immunopharmacology 2000;48:217-21

28 Otis AB, McKerrow CB, Bartlett RA, et al. Mechanical factors in distribution of pulmonary ventilation. J Appl Physiol 1956:8:427-43.

29 Fukuchi Y, Cosio M, Murphy B, et al. Intraregional basis for sequential filling and emptying of the lung. Respir Physiol 1980;41:253-66.

30 Tsoukias NM, George SC. A two-compartment model of pulmonary nitric oxide exchange dynamics. J Appl Physiol 1998;85:653-66.

\section{LUNG ALERT}

\section{Multislice CT scans and D-dimer assays may be the most practical strategy for diagnosing PE}

$\Delta$ Perrier A, Roy P-M, Sanchez O, et al. Multidector-row computed tomography in suspected pulmonary embolism. NEngl J Med 2005;352:1760-8

7

his prospective management trial with a 3 month follow up examined whether the use

of multidetector row computed tomographic (CT) scanning combined with D-dimer

ruled out pulmonary embolism (PE) safely without the use of lower limb ultrasonography, which has previously been shown to be needed along with single detector row CT scanning.

756 patients (of the 1014 screened: exclusion criteria included contraindications to contrast CT and other reasons for not participating in the study) attending the emergency departments of three teaching hospitals were investigated with a standard sequential protocol; 194 (26\%) were found to have PE. Of 82 patients with a high clinical probability, 78 had PE on the CT scan, one had a proximal deep vein thrombosis (DVT) with a negative CT scan, and three had negative ultrasound and CT scans as well as negative angiography. Of the remaining 674 patients without a high clinical probability of PE, 232 (34\%) had a negative D-dimer assay and an uneventful follow up. CT scanning showed PE in 109 patients, proximal DVT on ultrasonography with negative CT was found in two patients, and both CT scanning and ultrasonography were negative in 318 patients. The overall 3 month risk of thromboembolism among the 523 patients who did not have PE and were not receiving treatment was $1.0 \%$ (95\% CI 0.4 to 2.2 ). Even with the addition of the three patients with proximal DVT on ultrasonography and negative findings on CT scanning, the maximum 3 month risk would have been 1.5\% (95\% CI 0.8 to 3.0 ) if ultrasonography had not been included in the work up. This study indicates the potential clinical use of a diagnostic strategy using D-dimer assay and multidetector row CT scanning for ruling out PE without lower limb ultrasonography.

The limitations of the study include the large number of patients $(25 \%)$ excluded, so the results may not yet be generalisable. It was also not a true outcome study since venous ultrasonography was performed in all patients with an abnormal D-dimer level and those with DVT and no PE on CT scanning were anticoagulated. The results of this study will need evaluation in a proper outcome study where the decision to anticoagulate is made on the basis of CT scan results alone.

Z Ahmed

Registrar in Respiratory Medicine, Princess Royal Hospital, Telford, UK; zafarahmed@eircom.net 